\title{
RSP Revisitada \\ O São Francisco e a interligação com as bacias vizinhas
}

Lucas Lopes

Texto publicado na RSP, vol. 3, no 2, de agosto de 1952

A transposição do Rio São Francisco e a questão da segurança hídrica na área do semiárido nordestino sempre foram assuntos presentes na agenda política do Brasil. Na época do Império, a ideia já era vista por alguns intelectuais como a única solução para a seca do Nordeste. O projeto não foi iniciado então por falta de recursos da engenharia e de consenso na sociedade. Já na República, os Constituintes de 1946 determinaram a aplicação de 1\% das rendas da União para projetos de viabilização econômica do Rio, durante 20 anos. $\mathrm{O}$ artigo que revisitamos faz parte desse longo debate envolvendo o tema, que nos dias atuais se apresenta na iniciativa de transposição do Rio São Francisco, denominado "Projeto de Integração do Rio São Francisco com Bacias Hidrográficas do Nordeste Setentrional".

É interessante notar também a mudança do cenário político e social que precedeu os projetos anteriores que tinham o Rio São Francisco como objeto de intervenção. Como sabemos, o projeto atual foi cercado de debates sobre a função social do Rio e seus impactos ambientais e sociais na região. Trata-se de um debate legítimo e mostra a complexidade política e social que cerca essas grandes obras de engenharia. Para o gestor público, apresenta-se um problema não somente de logística e engenharia, mas também uma questão política e de "engenharia social". Basta lembrar as questões que envolvem a construção da Usina de Belo Monte, que emprega cerca de 20 mil trabalhadores, vindos de todos os lugares do Brasil. Não é difícil de entender a complexidade dessas obras.

'O problema das comunicações resume fatos 'fundamentalmente geográficos', por isto que entende com a maior ou menor permeabilidade das linhas fisiográficas e com a maior ou menor articulação dessas linhas com o mar.

O problema dos transportes resume fatos 'essencialmente bumanos', conseqüentemente variando com a época que se considere, isto é, segundo os recursos técnicos à disposição do homem".

(Mário Travassos - Introdução à Geografia das Comunicações Brasileiras)

Há muito vêm sendo aventadas idéias sôbre a intercomunicação de águas do São Francisco com outras bacias hidrográficas vizinhas. Algumas indicações que se propõem a desviar águas do São Francisco para irrigação de zonas sêcas do nordeste - serão 
estudadas em trabalho à parte. As que aquí serão examinadas se referem a possíveis extensões da rêde de navegação fluvial com destino a outras bacias, ou que visem melhorar a navegação do próprio São Francisco.

Quase tôdas elas foram apresentadas em épocas já remotas, quando não se previa a expansão de outros meios de transportes terrestres, e se utilizavam os rios na penetração do território, por piores que fôssem as suas condições de navegabilidade. As versões modernas dêsses projetos procuram justificar-se com a observação de trabalhos semelhantes de interligação de bacias em áreas altamente industrializadas da Europa e da América do Norte.

Com relação ao São Francisco, existem várias sugestões que foram atualizadas no estudo que apresentou, à Comissão de Revisão do Plano Geral de Viação Nacional, o Coronel Jaguaribe Gomes de Matos, em trabalho de fôlego, que é a primeira tentativa de elaboração de um Plano Nacional de Viação Fluvial.

A ligação do São Francisco ao Parnaíba, por meio de um canal navegável, do rio Prêto à lagoa de Parnaguá, já sugerida por Eduardo José de Morais, é lembrada pelo Coronel Jaguaribe em seu trabalho. De posse de uma cartografia mais completa e de informações recentes foram verificadas as dificuldades que êste empreendimento apresenta. As transposições possíveis do divisor entre as duas bacias se fariam em áreas de pequeníssima vazão e se desenvolveriam em extensões de grande declividade. Abrir canais, construir grandes açudes e numerosas comportas são obras exeqüíveis pela engenharia moderna. Entretanto não se justificam senão quando destinadas a uma exploração econômica. É o que acontece no projeto de ligação do São Francisco ao
Parnaíba, como no projeto de ligar o São Francisco ao Tocantins.

Os estudos procedidos pelo Engenheiro Rogério Teixeira Mendes, da C. V. S. F., mostram a inexeqüibilidade econômica de tais ligações nas próximas décadas.

Tais projetos nos fazem meditar sôbre o aforismo de Wellington: "A engenharia é muitas vezes a arte de não construir".

Um terceiro projeto que merece exame é o da interligação da bacia do rio Grande, afluente do Paraná, com o São Francisco. Em tôrno dessa intercomunicação de bacias, há duas idéias em curso - a primeira visando o problema da navegação, que foi desenvolvida pelo Coronel Jaguaribe de Matos, a segunda visando principalmente a formação de um potencial hidrelétrico artificial e o desvio de um contingente ponderável de água para melhoria do caudal do São Francisco em épocas de estiagem, foi estudado em 1945 pelo Engo Décio Vasconcelos, por determinação do Secretário de Viação de Minas de então, Eng ํㅡㄴ Lucas Lopes.

Dos estudos procedidos pela C. V. S. F. foi julgado inexeqüível, no momento, o projeto referente à navegação, por falta de fundamentos econômicos.

O projeto do Govêrno de Minas merece maior exame.

Já anteriormente, Horácio Williams no seu trabalho notável intitulado "Notas Geológicas e Econômicas sôbre o Rio do São Francisco" assim vislumbrava o problema:

"Em período geológico talvez não muito remoto, a bacia formada pelos rios Grande e Sapucaí, constituía a mais longínqua e mais alta cabeceira do rio São Francisco. A serra da Canastra encurvava-se para sudeste, na zona de Pium-í e, por meio dêste arco, encaminhava as águas no rumo do norte.

Depois, a ação solidária de outros agentes externos proporcionou a essas 
águas romperem aquêle arco, e cortarem uma passagem precipitada para a bacia do rio Paraná, definida no desfiladeiro de Jaguara. Aberto êsse canhão de Jaguara, as águas de ambas as bacias, assim divorciadas, baixaram e as erosões definiram mais e mais essa separação. A contribuição, assim perdida, faz falta sensível ao São Francisco, ao mesmo tempo que será sempre excessiva para os charcos do Paraná e para os seus saltos insuperáveis a bons transportes. Não é suntuosidade, nem poesia, prever que os vindouros (talvez os filhos de nossos netos) se decidam a aproveitar melhor a contribuição da bacia Grande-Sapucaí, reconduzindo-a para a bacia do São Francisco, por meio de rebaixamento da garganta de Pium-í; e então o São Francisco será navegável acima da barra do Paraopeba.

Os estudos procedidos pelo Govêrno de Minas conduziram às seguintes considerações, do Eng ${ }^{\circ}$ Décio Vasconcelos:

"Em Pôrto Capetinga, de acôrdo com os dados fornecidos pelo $2^{\circ}$ Distrito da Divisão de Águas do Ministério da Agricultura, a vazão mínima do rio Grande, cuja bacia hidrográfica é ali de 25.520 quilômetros quadrados, apresentou um valor médio de 180 metros cúbicos por segundo, para o período compreendido entre 1938 e 1942, correspondendo a uma contribuição unitária de 7,2 litros por segundo por quilômetro quadrado.

A vazão mínima do rio São Francisco em Pôrto Real, conforme elementos da mesma Repartição, apresentou um valor médio de 27,8 metros cúbicos por segundo, correspondendo a 5,75 litros por segundo por quilômetro quadrado, para uma bacia hidrográfica de 4.836 quilômetros quadrados.

Em Pirapora, para uma bacia hidrográfica de 61.539 quilômetros quadrados, a média das vazões mínimas verificadas no mesmo período foi de 200 metros cúbicos por segundo, sendo de 3,2 litros por segundo por quilômetro quadrado a respectiva contribuição unitária.

Bastam êstes elementos para se aquilatar da importância do empreendimento que visa tornar o São Francisco amplamente navegável, a partir de Pôrto Real, pois suas vazões mínimas nesse local ficariam equivalentes às verificadas hoje em Pirapora, 467 quilômetros a jusante.

De acôrdo com os estudos preliminares realizados, não há grandes dificuldades técnicas a vencer para execução do desvio proposto, cujas características econômicas são também satisfatórias.

Uma barragem no rio Grande, com apenas 10 metros de altura, localizada logo a jusante da barra do ribeirão Capetinga, elevará as águas do rio Grande até a cota 720 metros, invertendo o curso naquele seu tributário, numa extensão de 21 quilômetros, nas quais serão feitos trabalhos de alargamento e desobstrução do leito.

Numa extensão de 6 quilômetros será preciso a execução de cortes visando transpor o divisor de águas, sendo talvez necessária a construção de túnel apenas na extensão de 2 quilômetros, onde a altura do corte seria superior a 20 metros.

Transposto o divisor, as águas do rio Grande atingirão, já na bacia do São Francisco, as cabeceiras do córrego da Cafua, afluente do córrego da Limeira, que por sua vez lança suas águas no ribeirão dos Patos, tributário do São Francisco, onde tem sua barra cerca de 10 quilômetros a montante de Pôrto Real.

Neste trecho, de 45 quilômetros de extensão, serão realizados igualmente trabalhos de alargamento e desobstrução, a caixa do rio São Francisco, a jusante, já comportando vazões da ordem de $400 \mathrm{~m}^{3} / \mathrm{s}$. 
A transposição do divisor de águas proporcionará uma queda de 55 metros.

$\mathrm{Na}$ base de 180 metros cúbicos por segundo a potência permanente obtida será da ordem de $100.000 \mathrm{kw}$.

O desvio indicado não irá prejudicar o rio Grande em nenhum serviço de utilidade pública. De Pôrto Capetinga à barra do rio Sapucaí, o perfil acidentado do rio Grande impede qualquer tentativa de navegação. As corredeiras ali existentes, por outro lado, não apresentam condições favoráveis a aproveitamentos hidrelétricos de vulto, que poderiam talvez ser projetados, completivamente ao desvio proposto.

Cêrca de 50 quilômetros a jusante de Pôrto Capetinga, já recebe o rio Grande o seu principal afluente mineiro, o rio Sapucaí, curso d'água volumoso, com uma bacia hidrográfica de 24.853 quilômetros quadrados e uma vazão mínima da ordem de 170 metros cúbicos por segundo.

O volume d'água é, portanto, na barra do rio Sapucaí, sensìvelmente idêntico ao do rio Grande em Pôrto Capetinga.

A barragem de Pôrto Capetinga virá, ainda, represando as águas do rio Grande, melhorar as condições da navegação existente, no trecho Ribeirão Vermelho Capetinga.

Comportas de regularização permitirão limitar o desvio das águas do rio Grande nas proporções necessárias à navegação do São Francisco.

A Central Elétrica projetada no divisor de águas referido, nas imediações da vila de Pimenta, virá suprir de energia extensa região do Estado, compreendida pelos municípios de Pium-í, Pains, Pôrto Real, Arcos, Formiga, Guapé, Bambuí, Lagoa da Prata, e muitos outros".

A Comissão do Vale do São Francisco teve sua atenção voltada para êste problema que envolve obras de múltipla finalidade de grande interêsse. De fato uma contribuição de 180 metros cúbicos por segundo, introduzida nas nascentes do São Francisco, representaria um aumento substancial em Pirapora, onde a vazão média das mínimas gira em tôrno de 200 metros cúbicos por segundo, com reflexos favoráveis na navegação existente.

Acontece, porém, que as grandes obras de regularização do regime do São Francisco devem visar a retenção das grandes enchentes, tanto quanto a melhoria de tirante nas épocas de estiagem.

Se bem que a transposição do rio Grande para o São Francisco apresente múltiplas vantagens, tem o inconveniente de nada influir no controle das enchentes, mas, ao contrário, agravar, em pequena escala, os transbordamentos danosos.

Sendo uma obra de custo elevado, que não poderia ser conduzida ao mesmo tempo que as barragens de regularização no próprio São Francisco, julgou-se conveniente adiar a sua execução para época posterior.

A Comissão do São Francisco programou o estudo detalhado desta questão.

\section{O São Francisco e sua articu- lação com o mar}

"Acontece que o melhoramento do rio, assim como o transporte fluvial sôbre o rio melhorado, deve ser considerado em conexão com o transporte sôbre a ferrovia de junção (portage railway) em volta da catarata de Paulo Afonso; porquanto, sem a abertura e uso dessa linha férrea, é algum tanto duvidoso que o transporte por meio de vapores no Alto S. Francisco possa tornar-se proveitoso".

(W. Milnor Roberts - Relatório sôbre o S. Francisco) 
Se não existisse Paulo Afonso e os trechos encachoeirados de Sobradinho a Piranhas, se o São Francisco houvesse atingido, como nível de base de todo seu perfil de equilíbrio, o horizonte do Atlântico, se sua barra não se mostrasse tão repelente à fixação humana, se houvesse sido possível a penetração e o tráfego de gentes ao longo de todo seu caudal, outra seria a fisionomia do Brasil, de sua economia, de sua vida.

Penetrando barra acima, o São Francisco só é navegável numa extensão de cêrca de 228 quilômetros, por barcos de modesto calado. De Piranhas a Itaparica, em cêrca de 128 quilômetros, estende-se um trecho de utilização inviável para a navegação. O "canion" e a cachoeira de Paulo Afonso eliminam qualquer possibilidade de melhoria do rio para o tráfego de barcos. De Itaparica a Boa Vista, em cêrca de 270 quilômetros, inúmeras corredeiras e desníveis exigirão obras vultosas de canalização e represamento para que seja possível a navegação franca. De Boa Vista a Juàzeiro, em 120 quilômetros, o rio exige pequenos serviços para estabilizar uma navegação que já se procede em condições técnicas razoáveis.

Apenas de Juàzeiro a Pirapora, numa extensão ponderável de 1.370 quilômetros, pôde o rio ser navegado de forma satisfatória. De Sobradinho a Pirapora êle atingiu um perfil de equilíbrio que permite o tráfego, relativamente fácil, de barcas.

A idéia de se ligar o trecho médio navegável ao mar, por intermédio de canais laterais que contornassem o trecho encachoeirado, ou transpusessem as águas do São Francisco para as bacias do VazaBarris ou do Itapicuru, é, ainda em nossos dias, um sonho, em face do aspecto econômico que essas obras envolveriam.
Acreditamos, entretanto, que chegou o momento de se desenvolver um plano de articulação do trecho médio negável à seção inferior e ao mar, por intermédio de uma rêde de transportes terrestres.

Já analisamos a importância inegável da seção que vai de Pirapora a Juàzeiro e já mostramos que é justo esperar que a região por ela atravessada venha a presenciar, em breve, um surto razoável de progresso. Destacamos a importância das cidades gêmeas de Juàzeiro e Petrolina, como entrepostos comerciais de primeira grandeza, no interior são-franciscano.

Parece-nos que de Juàzeiro-Petrolina deve irradiar um sistema amplo de transportes terrestres, ligando-os ao mar e aos sertões vizinhos.

Naturalmente, a possibilidade de uma via de transportes de Juàzeiro ao baixo São Francisco, viria alargar a projeção desse núcleo de intercâmbio e permitir que os recursos naturais drenados pelo trecho médio navegável atingissem o baixo São Francisco.

Com a construção da Usina de Paulo Afonso e a eletrificação do Nordeste, surgem novas circunstâncias a alterar os têrmos primitivos do problema. A ligação de Juàzeiro a Piranhas por uma via férrea não teria mais a finalidade precípua de permitir o escoamento da produção do vale médio para o mar. Em vez disto, seria o elemento a possibilitar o tráfego de matérias-primas para um grande parque industrial em perspectiva.

De fato, existindo grandes disponibilidades de energia em Paulo Afonso, será lógica a formação de uma região industrial no Baixo São Francisco, que é a área do nordeste onde se encontra, além de outros, um fator essencial às grandes indústrias, especialmente químicas - água potável em grande abundância. Êsse parque industrial 
necessitará, provàvelmente, de matériasprimas provenientes do trecho médio navegável, que seriam transportadas pela ferrovia de Juàzeiro-Petrolina a PropriáPenedo a que nos referimos no estudo do Plano Ferroviário na Bacia do São Francisco.

A idéia de se incentivar a criação de um parque industrial, na região do baixo São Francisco, vem sendo analisada por uma Comissão especial de estudo sôbre a aplicação da energia de Paulo Afonso em indústrias eletroquímicas e eletrometalúrgicas. Sua viabilidade tornar-se-á mais forte quando estiver ligado o baixo ao médio São Francisco por via terrestre de boas condições técnicas.

A possibilidade de extensão da navegação a jusante de Juàzeiro e Boa Vista até Itaparica está, a nosso ver, condicionada ao plano de represamentos dos trechos encachoeirados, que sugeriram Geraldo Rocha, Mauricio Joppert, e a Organização Henrique Lage, visando, entre outras finalidades, grandes trabalhos de irrigação. Diz o professor Maurício Joppert: (*) "Os $428 \mathrm{~km}$ que vão da corredeira de Sobradinho a Jatobá (Itaparica), para serem melhorados constituem um problema tècnicamente mais difícil. Parece-nos, porém, que a questão deve ser encarada de um ponto de vista mais amplo, isto é, não reduzindo o São Francisco apenas ao papel secundário de uma via navegável mas, considerando que êle se intromete e consegue atravessar, com um saldo final de 600 $\mathrm{m}^{3} / \mathrm{s}$, uma das regiōes mais sêcas do nordeste brasileiro, é, assim, um verdadeiro presente divino que o homem tem de aproveitar para transformar o semideserto num dos paraísos criados pelas maravithas da irrigação".

Esta nos parece, realmente, a tese acertada sôbre os problemas do trecho encachoeirado, o que isola o baixo e o médio São Francisco. A possibilidade de se criarem áreas de irrigação perene no coração da região sêca do nordeste, deve ser o primeiro objetivo da série de barragens indicadas por aquêles técnicos nacionais. A navegação dos trechos represados será um subproduto do esquema principal, como o será a geração de energia.

Com êste pensamento em mente iniciamos, na Comissão do Vale do São Francisco, o estudo do problema, lutando de início com uma grande deficiência de cartografia adequada. O esquema que sugerimos para prosseguimento dos estudos é o seguinte: A Comissão do Vale do São Francisco, juntamente com o Departamento Nacional de Obras Contra as Sêcas, estudará um conjunto de obras de represamento e irrigação no trecho de Sobradinho a Itaparica. A Comissão do Vale do São Francisco se incumbirá de detalhar os projetos das barragens de derivação e eclusagem, incumbindo-se, posteriormente, de sua execução. O Departamento Nacional de Obras Contra as Sêcas fará estudos de canalização lateral, inclusive os açudes de transposição de vales, incumbindo-se de sua execução e das obras complementares de irrigação.

Esta cooperação é lógica e indispensável, em face da deficiência de recursos à disposição da Comissão do Vale do São Francisco.

Finalmente devemo-nos referir ao problema da barra do São Francisco.

Enquanto não existir na seção inferior do rio uma grande atividade econômica, enquanto não se tornar iminente a formação de um grande parque industrial no baixo São Francisco, e sua ligação ferroviária ao médio, não será aconselhável a inversão de grandes somas na desobstrução de sua barra. $\mathrm{O}$ acesso marítimo se faz hoje até Penedo por embarcações de cabotagem de 2.000 toneladas. A abertura e proteção de um canal de acesso para navios 
de 10.000 toneladas, que tornaria Penedo um pôrto de proporções oceânicas é uma obra cara, já estudada em todos os detalhes pelo Eng A. E. F. Portugal, que hoje presta uma valiosa colaboração à Comissão do Vale São Francisco, e orçada em duzentos milhões de cruzeiros.

A inversão dessa importância vultosa não se compreende quando as portas de Aracaju e Maceió, a curta distância da barra do São Francisco, e servindo a dois entrepostos comerciais de importância, estão a exigir da Nação trabalhos essenciais de acesso, acostamento e aparelhamento.

O problema da barra do São Francisco é caracterìsticamente a questão de mais um pôrto marítimo em nosso litoral e deverá ser resolvida de acôrdo com a política de aparelhamento portuário que adotar o Departamento Nacional de Portos.

\section{Nota}

(*) Maurício Joppert da Silva - Problemas Nacionais - Rio - 1943. 